\title{
Relationships between dust level and byssinosis and bronchitis in Lancashire cotton mills
}

\author{
G. BERRY ${ }^{1}$, M. K. B. MOLYNEUX ${ }^{2 *}$, and J. B. L. TOMBLESON ${ }^{3}$ \\ Medical Research Council's Pneumoconiosis Unit, Penarth, Glamorgan'1, Department of \\ Occupational Health, University of Manchester ${ }^{2}$, and HM Medical Inspectorate of Factories ${ }^{3}$
}

\begin{abstract}
Berry, G., Molyneux, M. K. B., and Tombleson, J. B. L. (1974). British Journal of Industrial Medicine, 31, 18-27. Relationships between dust level and byssinosis and bronchitis in Lancashire cotton mills. A prospective survey of workers in 14 cotton and two man-made fibre spinning mills was carried out. A questionnaire on respiratory symptoms was completed at the start of the survey by 1359 cotton workers and 227 workers in man-made fibre mills and again two years later by about half of these workers. Dust measurements were available for 772 women and 234 men cotton workers.

The prevalence of bronchitis was found to be unrelated to dust level but for women was related to years of exposure. The change in symptoms of bronchitis was unrelated to dust level or to length of exposure. There was, however, an increased prevalence of bronchitis in the cotton mills when compared with the man-made fibre mills, and also over the two-year period a greater proportion of symptom-free workers developed symptoms and a lower proportion of those with symptoms lost their symptoms in the cotton mills than in the manmade fibre mills.

The prevalence of byssinosis was related to smoking habits, the smokers having about 1.4 times as much byssinosis as the non- and ex-smokers after allowing for exposure. Byssinosis was associated with the dust level and years of exposure, more so for the women, and an association between the incidence of new cases over the two years and dust level was also found. After allowing for dust level, years of exposure, and smoking there were still differences between the occupational groups in byssinosis prevalence. Strippers and grinders had the highest prevalence followed by drawframe tenters. Speedframe tenters, card tenters, and comber tenters had similar prevalences and ring spinners the lowest.
\end{abstract}

In the three-year prospective survey of cotton workers described by Molyneux and Tombleson (1970) the prevalence of byssinosis was found to be higher in coarse mills than in medium mills and to vary with occupation. Also the prevalence of bronchitis was higher in those with byssinosis. The analysis of the acute and chronic changes in lung function was given by Berry et al. (1973), and the Monday fall in forced expired volume during the

*Present address: Department of Social and Occupational Medicine, University of Dundee. shift was related to dust level. In this paper the dose-response relationships between dust level and symptoms of byssinosis and bronchitis will be considered.

The relationship between the prevalence of byssinosis and dust concentration in cotton mills is important in assessing the safety of conditions and for deciding what concentration could be considered satisfactory from a hygienic viewpoint. The relationship of bronchitis to dust level is also relevant since, first, some workers may develop bronchitis instead of byssinosis as a result of their exposure to cotton 
dust, and, secondly, in an advanced stage byssinosis may not be easily distinguishable from chronic bronchitis (Schilling, 1956).

\section{Population and methods}

Details of the population, the grading of byssinosis and bronchitis, and the measurement of dust concentration were given in the earlier papers but the features relevant to this paper are summarized below.

The population defined comprised 1857 men and women between the ages of 15 and 65 working in the blowing, carding, and associated processes of 16 Lancashire mills, of which eight processed coarse cotton (count 1 to 24), six medium cotton (count 10 to 50), and two processed man-made fibre. Of these workers, 120 either refused to co-operate or were absent and 151 could not be questioned because they knew too little English. Of the 1586 workers seen, 1359 worked in cotton processing mills.

The mills were visited on six occasions at invervals of six months. The main purposes of the repeated visits were the measurement of lung function and dust sampling, but on the first occasion on which a worker was seen a respiratory questionnaire (Medical Research Council, 1960) with additional questions on chest tightness (Roach and Schilling, 1960) was completed. The questionnaire was completed on a second occasion, two years later, for 796 workers. Byssinosis was subdivided into three grades:

Grade $\frac{1}{2}$ Occasional chest tightness on Mondays

Grade I Chest tightness and/or difficulty in breathing on Mondays only

Grade II Chest tightness and/or difficulty in breathing on Mondays and other days.

The classification of bronchitis was based on that of the Medical Research Council (1966):

Grade 1 Chronic phlegm for at least three consecutive months each year but no acute exacerbations

Grade 2 Chronic phlegm, and also an attack of increased phlegm lasting three weeks or more and/or chest illness with increased phlegm causing absence from work of one week or more in the last three years

Grade 3 As grade 2 but with two or more attacks of increased phlegm and/or two or more chest illnesses.

The mass concentration of the respirable, medium, and fly components of total dust was measured at sites corresponding as far as was practicable to the working places of the operatives, and the modified Hexhlet and total samplers were run throughout the shifts when the mills were visited. Three components of dust were considered-respirable $(<7 \mu \mathrm{m}$ Stokes diameter), fine ( $<2 \mathrm{~mm}$ length), and total. The dust concentrations were estimated for 772 of the 793 women but for only 234 of the $566 \mathrm{men}$ in cotton mills. There were two reasons for the low latter figure; first, dust samples were not taken in the blowroom and cotton chamber where 144 men worked, and, secondly, some of the men moved frequently from one part of the mill to another, e.g., the 93 carders and undercarders and 67 labourers.

\section{Factors considered}

The prevalences of byssinosis and bronchitis have been examined taking account of the following factors:

(1) sex

(2) age-in five 10-year age groups from 15-24 to 55+

(3) exposure or years worked in cotton mills-in 10-year groups $0-9,10-19$, and $20+$

(4) dust concentrations-each component was subdivided into up to six ranges

(5) occupation when seen-six jobs in carding and associated processes

(6) smoking-non- or ex-smokers and smokers.

\section{Results}

\section{Bronchitis}

As observed by Molyneux and Tombleson (1970), there was more bronchitis in the cotton mills than in the man-made fibre mills, and also the prevalence was related to age and smoking. The relationship

\section{TABLE 1}

BRONCHITIS: RELATIONSHIP WITH LENGTH OF EXPOSURE

Years worked in mill

1Standardized for age and smoking (see text) 
TABLE 2

Byssinosis: Relationship with Dust Concentration and Length of Exposure for Women

\begin{tabular}{|c|c|c|c|c|c|c|c|c|c|c|c|c|}
\hline \multirow{5}{*}{$\begin{array}{c}\text { Dust } \\
\text { concentration } \\
\left(m g / m^{3}\right)\end{array}$} & \multicolumn{12}{|c|}{ Length of exposure to cotton (years) } \\
\hline & \multicolumn{4}{|c|}{$0-9$} & \multicolumn{4}{|c|}{$10-19$} & \multicolumn{4}{|c|}{$20+$} \\
\hline & \multirow[b]{3}{*}{$n$} & \multicolumn{11}{|c|}{ Number of subjects and percentages with byssinosis } \\
\hline & & \multicolumn{3}{|c|}{ Grade } & & \multicolumn{3}{|c|}{ Grade } & & \multicolumn{3}{|c|}{ Grade } \\
\hline & & $\frac{1}{2}-I I$ & $I+I I$ & II & $n$ & $\frac{1}{2}-I I$ & $I+I I$ & II & $n$ & $\frac{1}{2}-I I$ & $I+I I$ & II \\
\hline $\begin{array}{r}\text { Respirable } \\
0 \cdot 11-0 \cdot 19 \\
0 \cdot 20-0 \cdot 29 \\
0.30-0 \cdot 39 \\
0.40-0 \cdot 49 \\
0.50-0 \cdot 69 \\
0.70-1 \cdot 41\end{array}$ & $\begin{array}{r}8 \\
19 \\
26 \\
69 \\
24 \\
43\end{array}$ & $\begin{array}{r}0.0 \\
0.0 \\
11.5 \\
5.8 \\
25.0 \\
20.4\end{array}$ & $\begin{array}{r}0.0 \\
0.0 \\
0.0 \\
4.3 \\
16.7 \\
14.0\end{array}$ & $\begin{array}{l}0.0 \\
0.0 \\
0.0 \\
1.4 \\
4.2 \\
0.0\end{array}$ & $\begin{array}{l}13 \\
32 \\
27 \\
47 \\
17 \\
32\end{array}$ & $\begin{array}{r}7 \cdot 7 \\
21 \cdot 9 \\
33 \cdot 3 \\
19 \cdot 1 \\
23 \cdot 5 \\
28 \cdot 1\end{array}$ & $\begin{array}{r}7 \cdot 7 \\
18 \cdot 8 \\
18 \cdot 5 \\
14 \cdot 9 \\
17 \cdot 6 \\
21 \cdot 9\end{array}$ & $\begin{array}{r}0.0 \\
6 \cdot 2 \\
11 \cdot 1 \\
4.3 \\
5.9 \\
9.4\end{array}$ & $\begin{array}{r}38 \\
119 \\
36 \\
130 \\
48 \\
44\end{array}$ & $\begin{array}{l}28.9 \\
26 \cdot 9 \\
22.2 \\
27 \cdot 7 \\
47.9 \\
56 \cdot 8\end{array}$ & $\begin{array}{l}23 \cdot 7 \\
19 \cdot 3 \\
22 \cdot 2 \\
20 \cdot 8 \\
35 \cdot 4 \\
43 \cdot 2\end{array}$ & $\begin{array}{r}5 \cdot 3 \\
10 \cdot 1 \\
11 \cdot 1 \\
3 \cdot 1 \\
14 \cdot 6 \\
15 \cdot 9\end{array}$ \\
\hline $\begin{array}{l}\text { Fine } \\
0 \cdot 25-0.49 \\
0 \cdot 50-0 \cdot 74 \\
0.75-0.99 \\
1 \cdot 00-1 \cdot 24 \\
1 \cdot 25-1 \cdot 49 \\
1 \cdot 50-2 \cdot 38\end{array}$ & $\begin{array}{l}18 \\
41 \\
24 \\
50 \\
43 \\
13\end{array}$ & $\begin{array}{r}0.0 \\
2.4 \\
20 \cdot 8 \\
8.0 \\
18 \cdot 6 \\
30 \cdot 8\end{array}$ & $\begin{array}{r}0.0 \\
0.0 \\
8.3 \\
6.0 \\
9.3 \\
30.8\end{array}$ & $\begin{array}{l}0.0 \\
0.0 \\
4.2 \\
0.0 \\
2.3 \\
0.0\end{array}$ & $\begin{array}{l}26 \\
35 \\
36 \\
30 \\
29 \\
12\end{array}$ & $\begin{array}{l}19 \cdot 2 \\
14 \cdot 3 \\
19 \cdot 4 \\
26 \cdot 7 \\
31 \cdot 0 \\
41 \cdot 7\end{array}$ & $\begin{array}{l}15 \cdot 4 \\
11 \cdot 4 \\
11 \cdot 1 \\
20 \cdot 0 \\
24 \cdot 1 \\
33 \cdot 3\end{array}$ & $\begin{array}{r}3 \cdot 8 \\
2.9 \\
8 \cdot 3 \\
6 \cdot 7 \\
10 \cdot 3 \\
8.3\end{array}$ & $\begin{array}{r}95 \\
105 \\
77 \\
51 \\
79 \\
8\end{array}$ & $\begin{array}{l}25.3 \\
21.9 \\
32.5 \\
25 \cdot 5 \\
54 \cdot 4 \\
87.5\end{array}$ & $\begin{array}{l}18 \cdot 9 \\
17 \cdot 1 \\
24 \cdot 7 \\
15 \cdot 7 \\
43 \cdot 0 \\
75 \cdot 0\end{array}$ & $\begin{array}{r}8.4 \\
6.7 \\
6.5 \\
13.7 \\
11.4 \\
0.0\end{array}$ \\
\hline $\begin{array}{l}\text { Total } \\
0 \cdot 67-0 \cdot 99 \\
1 \cdot 00-1 \cdot 49 \\
1 \cdot 50-1 \cdot 99 \\
2 \cdot 00-2 \cdot 74 \\
2 \cdot 75-3 \cdot 49 \\
3 \cdot 50-7 \cdot 20\end{array}$ & $\begin{array}{l}37 \\
15 \\
26 \\
41 \\
38 \\
32\end{array}$ & $\begin{array}{r}2.7 \\
6 \cdot 7 \\
11 \cdot 5 \\
12.2 \\
7.9 \\
28 \cdot 1\end{array}$ & $\begin{array}{r}0.0 \\
6 \cdot 7 \\
3 \cdot 8 \\
7 \cdot 3 \\
2.6 \\
21.9\end{array}$ & $\begin{array}{l}0.0 \\
0.0 \\
0.0 \\
2.4 \\
0.0 \\
3.1\end{array}$ & $\begin{array}{l}42 \\
17 \\
22 \\
29 \\
29 \\
29\end{array}$ & $\begin{array}{l}19 \cdot 0 \\
11 \cdot 8 \\
36.4 \\
10 \cdot 3 \\
20 \cdot 7 \\
41 \cdot 4\end{array}$ & $\begin{array}{r}14.3 \\
11.8 \\
22.7 \\
6.9 \\
13.8 \\
34.5\end{array}$ & $\begin{array}{r}4.8 \\
0.0 \\
13.6 \\
0.0 \\
10.3 \\
10.3\end{array}$ & $\begin{array}{r}114 \\
77 \\
41 \\
52 \\
73 \\
58\end{array}$ & $\begin{array}{l}22 \cdot 8 \\
26 \cdot 0 \\
24 \cdot 4 \\
34 \cdot 6 \\
35 \cdot 6 \\
60 \cdot 3\end{array}$ & $\begin{array}{l}19 \cdot 3 \\
16.9 \\
22.0 \\
21 \cdot 2 \\
26.0 \\
50.0\end{array}$ & $\begin{array}{r}9.6 \\
3.9 \\
9.8 \\
3.8 \\
16.4 \\
6.9\end{array}$ \\
\hline No measurements & 9 & $22 \cdot 2$ & $22 \cdot 2$ & 0.0 & 7 & $42 \cdot 9$ & $14 \cdot 3$ & 0.0 & 5 & $40 \cdot 0$ & $40 \cdot 0$ & 0.0 \\
\hline
\end{tabular}

with dust level and length of exposure has been examined by fitting additive logit models to the data, taking account of these two factors and also age and smoking. In fact for neither sex was there any effect due to dust concentration and this factor was excluded from the analysis. For each sex separately the data were regarded therefore as a 3 lengths of exposure $\times 10$ combinations of age and smoking habit table of prevalences. Then prevalences, standardized for age and smoking, were calculated by applying the direct method to the fitted prevalences in each cell (Berry, 1970).

The results are given in Table 1 and also the prevalences in the man-made fibre mills adjusted to the age/smoking distribution in the cotton mills by the direct method. For women, and all severities of bronchitis, there is a positive trend in the bronchitis prevalences with increasing length of exposure $(P<0.05)$. However, this trend is not present in men for whom differences due to length of exposure are not significant.

Comparing the prevalences in the man-made fibre mills with those in the cotton mills invariably favours the former but not significantly so for the women.
Although the differences are nominally significant for the men, the validity of the test depends on the mills being representative, a point discussed below. The comparison for women is complicated by the anomaly that in the man-made fibre mills the bronchitis prevalences for women are higher for non-smokers than smokers (Molyneux and Tombleson, 1970), and for smokers the difference between the two types of mill is significant.

\section{Byssinosis}

The data on byssinosis prevalence are set out in detail for women in Table 2 and for men in Table 3. In these tables the dust concentration is given in terms of respirable, fine, and total, and the preprevalences of byssinosis are expressed in three ways according to severity-grades $\frac{1}{2}$, I, and II combined, grades I and II combined, and grade II only.

In Table 4 the association between byssinosis and smoking is illustrated for grades I and II combined, taking account of fine dust concentration and years of exposure. For the women the prevalences of byssinosis were greater for the smokers than for the 
TABLE 3

Byssinosis: Relationship with Dust Concentration and Length of Exposure for Men

\begin{tabular}{|c|c|c|c|c|c|c|c|c|c|c|c|c|}
\hline \multirow{5}{*}{$\begin{array}{c}\text { Dust } \\
\text { concentration } \\
\left(\mathrm{mg} / \mathrm{m}^{3}\right)\end{array}$} & \multicolumn{12}{|c|}{ Length of exposure to cotton (years) } \\
\hline & \multicolumn{4}{|c|}{$0-9$} & \multicolumn{4}{|c|}{$10-19$} & \multicolumn{4}{|c|}{$20+$} \\
\hline & \multirow[b]{3}{*}{$n$} & \multicolumn{8}{|c|}{ Number of subjects and percentages with byssinosis } & & & \\
\hline & & \multicolumn{3}{|c|}{ Grade } & & \multicolumn{3}{|c|}{ Grade } & & \multicolumn{3}{|c|}{ Grade } \\
\hline & & $\frac{1}{2}-$ II & $\mathbf{I}+\mathbf{I I}$ & II & $n$ & $\frac{1}{2}-$ II & $\mathbf{I}+\mathbf{I I}$ & II & $n$ & $\frac{1}{2}-\mathrm{II}$ & $\mathbf{I}+\mathbf{I I}$ & II \\
\hline $\begin{array}{c}\text { Respirable } \\
0 \cdot 11-0 \cdot 19 \\
0 \cdot 20-0 \cdot 29 \\
0 \cdot 30-0 \cdot 39 \\
0 \cdot 40-0 \cdot 49 \\
0 \cdot 50-0 \cdot 69 \\
0 \cdot 70-1 \cdot 41\end{array}$ & $\begin{array}{r}2 \\
10 \\
6 \\
31 \\
6 \\
34\end{array}$ & $\begin{array}{r}0.0 \\
0.0 \\
16.7 \\
22.6 \\
16.7 \\
17.6\end{array}$ & $\begin{array}{r}0.0 \\
0.0 \\
16.7 \\
19.4 \\
16.7 \\
14.7\end{array}$ & $\begin{array}{l}0.0 \\
0.0 \\
0.0 \\
0.0 \\
0.0 \\
2.9\end{array}$ & $\begin{array}{r}1 \\
11 \\
7 \\
37 \\
5 \\
28\end{array}$ & $\begin{array}{r}0 \cdot 0 \\
45 \cdot 5 \\
14 \cdot 3 \\
51 \cdot 4 \\
80 \cdot 0 \\
57 \cdot 1\end{array}$ & $\begin{array}{r}0 \cdot 0 \\
27 \cdot 3 \\
14 \cdot 3 \\
43 \cdot 2 \\
60 \cdot 0 \\
53 \cdot 6\end{array}$ & $\begin{array}{r}0.0 \\
9 \cdot 1 \\
0.0 \\
16 \cdot 2 \\
0.0 \\
10.7\end{array}$ & $\begin{array}{r}0 \\
9 \\
6 \\
22 \\
1 \\
18\end{array}$ & $\begin{array}{r}\overline{88.9} \\
66 \cdot 7 \\
36 \cdot 4 \\
0.0 \\
72 \cdot 2\end{array}$ & $\begin{array}{r}\overline{66 \cdot 7} \\
50 \cdot 0 \\
27 \cdot 3 \\
0 \cdot 0 \\
61 \cdot 1\end{array}$ & $\begin{array}{r}\overline{55.6} \\
33 \cdot 3 \\
13.6 \\
0.0 \\
27.8\end{array}$ \\
\hline $\begin{array}{l}\text { Fine } \\
0 \cdot 25-0 \cdot 49 \\
0 \cdot 50-0 \cdot 74 \\
0 \cdot 75-0 \cdot 99 \\
1 \cdot 00-1 \cdot 24 \\
1 \cdot 25-1 \cdot 49 \\
1 \cdot 50-2 \cdot 38\end{array}$ & $\begin{array}{r}5 \\
14 \\
21 \\
11 \\
30 \\
8\end{array}$ & $\begin{array}{r}0.0 \\
7 \cdot 1 \\
28.6 \\
9 \cdot 1 \\
16.7 \\
25.0\end{array}$ & $\begin{array}{r}0.0 \\
7 \cdot 1 \\
23 \cdot 8 \\
9 \cdot 1 \\
13 \cdot 3 \\
25 \cdot 0\end{array}$ & $\begin{array}{l}0.0 \\
0.0 \\
0.0 \\
0.0 \\
3.3 \\
0.0\end{array}$ & $\begin{array}{r}2 \\
10 \\
40 \\
11 \\
18 \\
8\end{array}$ & $\begin{array}{r}0.0 \\
50 \cdot 0 \\
42 \cdot 5 \\
72 \cdot 7 \\
55 \cdot 6 \\
62.5\end{array}$ & $\begin{array}{r}0.0 \\
30.0 \\
35.0 \\
63.6 \\
55.6 \\
50.0\end{array}$ & $\begin{array}{r}0.0 \\
10.0 \\
15.0 \\
9.1 \\
5.6 \\
12.5\end{array}$ & $\begin{array}{r}0 \\
12 \\
18 \\
12 \\
5 \\
9\end{array}$ & $\begin{array}{c}-\overline{66 \cdot 7} \\
66 \cdot 7 \\
16 \cdot 7 \\
80 \cdot 0 \\
77 \cdot 8\end{array}$ & $\begin{array}{r}- \\
50 \cdot 0 \\
50 \cdot 0 \\
8 \cdot 3 \\
80 \cdot 0 \\
66.7\end{array}$ & $\begin{array}{r}\overline{41 \cdot 7} \\
27 \cdot 8 \\
0 \cdot 0 \\
40 \cdot 0 \\
33 \cdot 3\end{array}$ \\
\hline $\begin{array}{l}\text { Total } \\
0 \cdot 67-0 \cdot 99 \\
1 \cdot 00-1 \cdot 49 \\
1 \cdot 50-1 \cdot 99 \\
2 \cdot 00-2 \cdot 74 \\
2 \cdot 75-3 \cdot 49 \\
3 \cdot 50-7 \cdot 20\end{array}$ & $\begin{array}{l}11 \\
17 \\
11 \\
26 \\
14 \\
10\end{array}$ & $\begin{array}{r}9 \cdot 1 \\
29 \cdot 4 \\
9 \cdot 1 \\
7 \cdot 7 \\
28 \cdot 5 \\
20 \cdot 0\end{array}$ & $\begin{array}{r}9 \cdot 1 \\
23 \cdot 5 \\
9 \cdot 1 \\
7 \cdot 7 \\
21 \cdot 4 \\
20 \cdot 0\end{array}$ & $\begin{array}{l}0.0 \\
0.0 \\
0 \cdot 0 \\
0 \cdot 0 \\
7 \cdot 1 \\
0 \cdot 0\end{array}$ & $\begin{array}{r}18 \\
37 \\
15 \\
10 \\
15 \\
5\end{array}$ & $\begin{array}{l}50 \cdot 0 \\
45 \cdot 9 \\
53 \cdot 3 \\
70 \cdot 0 \\
46 \cdot 7 \\
50 \cdot 0\end{array}$ & $\begin{array}{l}25.0 \\
37 \cdot 8 \\
46.7 \\
70.0 \\
40.0 \\
50.0\end{array}$ & $\begin{array}{r}12.5 \\
16.2 \\
0.0 \\
10 \cdot 0 \\
6 \cdot 7 \\
25 \cdot 0\end{array}$ & $\begin{array}{r}6 \\
15 \\
9 \\
7 \\
10 \\
9\end{array}$ & $\begin{array}{l}83 \cdot 3 \\
73 \cdot 3 \\
44 \cdot 4 \\
42 \cdot 9 \\
50 \cdot 0 \\
55 \cdot 6\end{array}$ & $\begin{array}{l}50 \cdot 0 \\
60 \cdot 0 \\
33 \cdot 3 \\
42 \cdot 9 \\
50 \cdot 0 \\
33 \cdot 3\end{array}$ & $\begin{array}{r}50 \cdot 0 \\
33 \cdot 3 \\
22 \cdot 2 \\
28 \cdot 6 \\
30 \cdot 0 \\
0 \cdot 0\end{array}$ \\
\hline No measurements & 173 & $7 \cdot 5$ & $3 \cdot 5$ & $1 \cdot 2$ & 91 & $29 \cdot 7$ & $22 \cdot 0$ & $6 \cdot 6$ & 68 & $39 \cdot 7$ & $26 \cdot 5$ & $13 \cdot 2$ \\
\hline
\end{tabular}

TABLE 4

Byssinosis: Relationship with Fine Dust Concentration, Length of Exposure, and Smoking

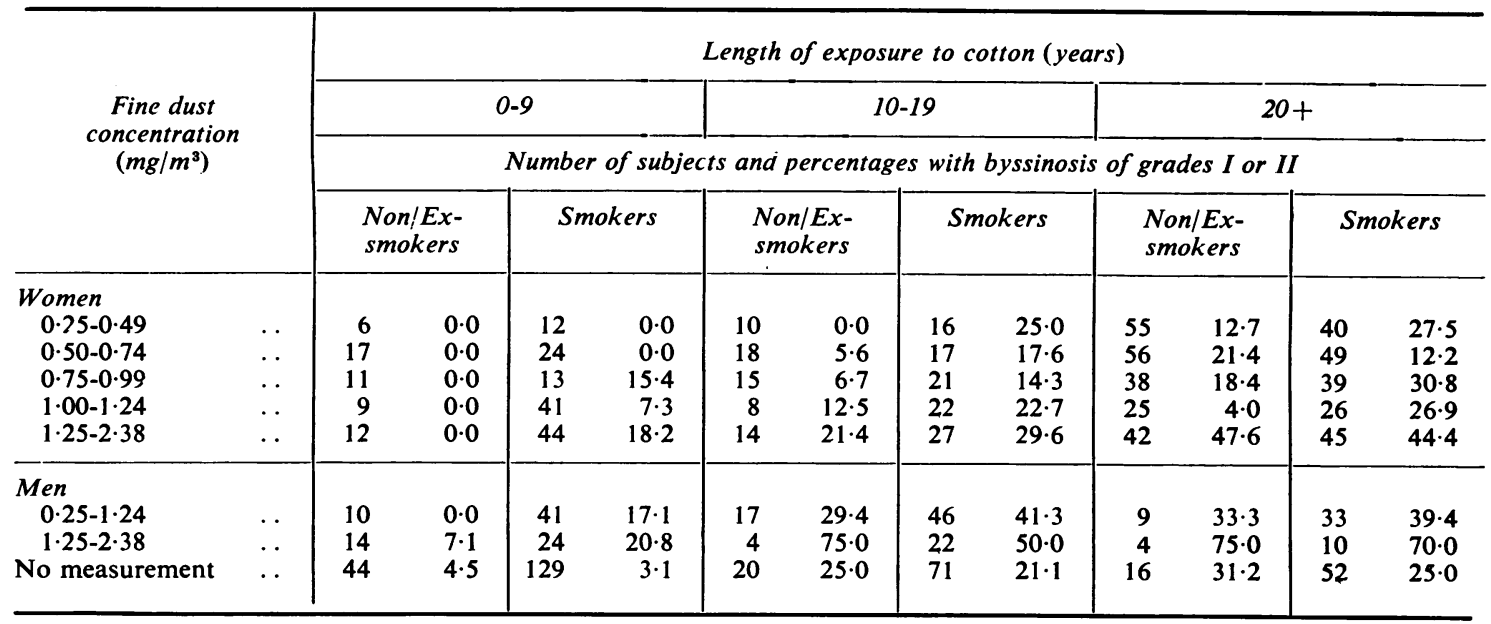


TABLE 5

Byssinosis: Association with Smoking and Sex AFTER ALlOWING FOR Fine Dust CONCENTRATION AND LENGTH OF EXPOSURE

\begin{tabular}{l|c|c|c}
\hline & \multicolumn{3}{|c}{$\begin{array}{c}\text { Standardized } \\
\text { of byssinosis } \\
(\%)\end{array}$} \\
\cline { 2 - 4 } & \multicolumn{3}{|c}{ Grade of byssinosis } \\
\cline { 2 - 4 } & $\frac{1}{2}$, I, II & I, II & II \\
\hline Women non/ex-smokers & 20.2 & 14.4 & 5.0 \\
Women smokers & 29.0 & 21.9 & 6.9 \\
\hline Men non/ex-smokers & 32.0 & 28.5 & 11.6 \\
Men smokers & 44.9 & 37.1 & 14.6
\end{tabular}

IStanclaraized for tine dust concentration and length of exposure

non/ex-smokers in most of the combinations of dust concentration and length of exposure. For the men the trend is in the same direction but not so clear. Also from Table 4 it is seen that the prevalences were higher for men than for women with the same dust level and length of exposure both for non/exsmokers and for smokers. These associations have been examined formally by fitting additive logit models to the data, regarded as a 6 dust levels $\times$ 3 lengths of exposure $\times 4$ combinations of sex and smoking habit table of prevalences.

In Table 5 the resulting standardized prevalences are shown using the fine component of dust. Similar values were obtained when the dust concentration was allowed for in terms of the respirable or total components. All severities of byssinosis show the same pattern, i.e., an effect of both smoking and sex, the latter being larger so that the standardized prevalences are higher for men who do not smoke than for women smokers. The differences between men and women are significant $(\mathbf{P}<0.01)$ for all severities and the smoking effect is significant $(P<0.05)$ except for grade II alone.

We now return to the relationship between byssinosis prevalence and dust concentration and length of exposure. The proportion of smokers varies considerably, e.g., $71 \%$ of women with less than 10 years' exposure smoked compared with $61 \%$ in the $10-19$ years' group and $48 \%$ with over 20 years' exposure. Therefore the results have been standardized for smoking. The prevalence for each combination of dust concentration and length of exposure has been adjusted to the proportion of smokers in the whole population, i.e., to $56 \%$ for women and $76 \%$ for men. The relationship between the standardized prevalence (grades I and II combined), length of exposure, and respirable dust concentration for
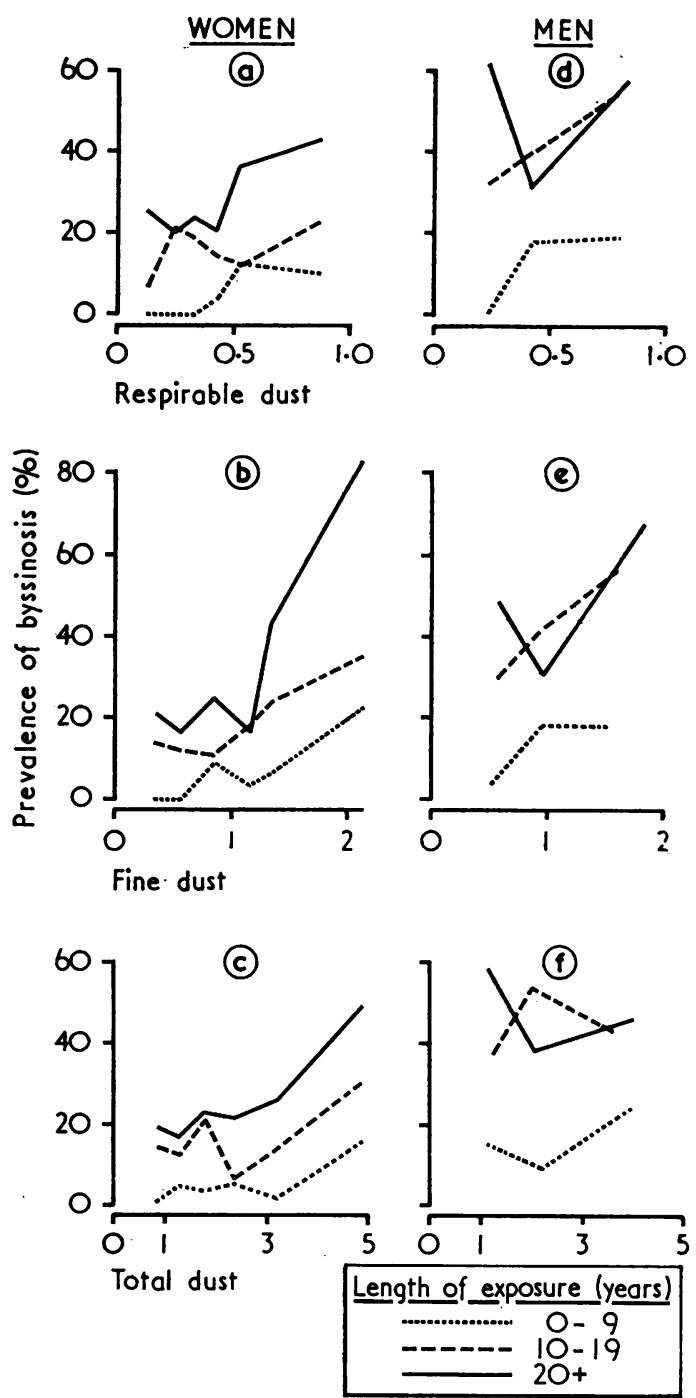

FIG. 1. Relationships between the prevalence of byssinosis (grades I and II combined), length of exposure, and concentration of dust. The prevalences have been adjusted for smoking for men and women separately (see text): (a and d) respirable dust ( $<7 \mu \mathrm{m}$ Stokes diameter); (b and e) fine dust ( $<2 \mathrm{~mm}$ length); and (c and f) total dust, all in $\mathrm{mg} / \mathrm{m}^{3}$.

women is shown in Fig. 1a, using fine and total dust in Fig. $1 b$ and c, and for men in Fig. 1d, e, and f.

The prevalence increases through the three lengths of exposure for the women, but for the men the group with more than 20 years' exposure has an overall prevalence similar to that for the group with between 10 and 20 years' exposure. There is an increase in byssinosis prevalence with increasing dust concentration for fine and total dust in women, and 
TABLE 6

Byssinosis: Prevalence AND OcCupation

\begin{tabular}{|c|c|c|c|c|c|c|c|c|}
\hline \multirow{3}{*}{ Occupation } & \multirow{3}{*}{$\begin{array}{c}\text { No. } \\
\text { of } \\
\text { subjects }\end{array}$} & \multirow{3}{*}{$\begin{array}{c}\text { Mean fine } \\
\text { dust concentration } \\
\left(m g / m^{3}\right)\end{array}$} & \multicolumn{6}{|c|}{ Prevalence of byssinosis (\%) } \\
\hline & & & \multicolumn{3}{|c|}{ Crude } & \multicolumn{3}{|c|}{ Standardized $^{1}$} \\
\hline & & & $\frac{1}{2}-I I$ & $I+I I$ & II & $\frac{1}{2}-I I$ & $I+I I$ & II \\
\hline $\begin{array}{l}\text { Comber tenter (women) } \\
\text { Speedframe tenter (women) } \\
\text { Ring spinner (women) } \\
\text { Drawframe tenter (women) } \\
\text { Card tenter (women) } \\
\text { Stripper \& grinder (men) }\end{array}$ & $\begin{array}{l}46 \\
377 \\
108 \\
141 \\
100 \\
167\end{array}$ & $\begin{array}{l}0.51 \\
0.82 \\
0.97 \\
0.95 \\
1 \cdot 26 \\
1 \cdot 11\end{array}$ & $\begin{array}{l}10 \cdot 9 \\
28 \cdot 6 \\
11 \cdot 1 \\
36 \cdot 9 \\
19 \cdot 0 \\
53 \cdot 9\end{array}$ & $\begin{array}{r}6 \cdot 5 \\
21 \cdot 8 \\
7 \cdot 4 \\
27 \cdot 0 \\
14 \cdot 0 \\
44 \cdot 3\end{array}$ & $\begin{array}{r}0 \cdot 0 \\
6 \cdot 4 \\
3 \cdot 7 \\
14 \cdot 2 \\
1 \cdot 0 \\
15 \cdot 6\end{array}$ & $\begin{array}{l}24 \cdot 8 \\
24 \cdot 6 \\
15 \cdot 9 \\
36 \cdot 4 \\
20 \cdot 2 \\
47 \cdot 6\end{array}$ & $\begin{array}{l}15 \cdot 5 \\
18 \cdot 0 \\
11 \cdot 4 \\
27 \cdot 1 \\
16 \cdot 0 \\
38 \cdot 8\end{array}$ & $\begin{array}{r}0 \cdot 0 \\
5 \cdot 6 \\
3 \cdot 8 \\
14 \cdot 1 \\
1 \cdot 4 \\
13 \cdot 1\end{array}$ \\
\hline
\end{tabular}

1Standardized for fine dust concentration, length of exposure, and smoking

for men with less than 20 years' exposure with respirable and fine dust.

After standardizing for smoking, dust concentration, and length of exposure, the byssinosis prevalences are similar in mills processing medium cotton to those in mills using coarse cotton; in fact the medium mills have the slightly higher standardized prevalences. Therefore, the higher prevalences in the coarse mills reported by Molyneux and Tombleson (1970) may be explained in terms of the higher dust concentrations.

Turning now to occupation, in Table 6 the main jobs for which there were dust measurements are given with the mean concentration of fine dust and the prevalence of byssinosis. As the jobs have different dust concentrations and different mean lengths of exposure, ranging from 11 years for card tenters to 27 years for speedframe tenters, standardized prevalences are also given. These have been calculated by the indirect method allowing also for smoking. There were significant $(P<0.001)$ differences between the occupations. The highest overall standardized prevalences were for strippers and grinders. Of the jobs carried out by women, drawframe tenters had high prevalences, ring spinners had low prevalences, while speedframe tenters, card tenters, and comber tenters had similar intermediate values. Because of the small numbers with grade 2 byssinosis in some jobs, e.g., there was only one such case for ring-spinners, the grade 2 prevalences are accordingly less accurate.

\section{Change of symptoms}

There were 669 cotton workers, who completed a repeat questionnaire two years after the first, and in addition 127 subjects working in the man-made fibre mills. For both bronchitis and byssinosis we have calculated the incidence of new cases among those initially without symptoms and the remission rate of existing cases. For this purpose we have reduced both diseases to dichotomies by combining all grades of bronchitis, including grade $\frac{1}{2}$, with non-byssinotics and combining byssinosis grades I and II.

The half of the population with a repeat questionnaire is not fully representative of the total population seen. First, there is a deficiency of short-term workers due to some having left before the repeat questionnaire was due. Secondly, a greater proportion $(56 \%)$ of non/ex-smokers completed a second questionnaire compared with smokers $(45 \%)$ but for women this difference was mainly a consequence of the deficiency of short-term workers. Thirdly, after allowing for length of exposure, the prevalence of byssinosis, as determined from the first questionnaire, for women is only $87 \%$ of that expected from the total population; however, the prevalences of byssinosis in men and bronchitis in both sexes are similar to those for the total population. Thus, as would be expected, those who completed a second questionnaire are representative of workers remaining in the industry, apart from a slight tendency of those with disease to be absent when their second questionnaire was due.

The incidence and remission rates have been tabulated in relation to length of exposure and smoking, and for byssinosis also to fine dust concentration (Table 7). For bronchitis there was no relationship between either the development of new cases or the remission of existing ones and dust concentration. However, the comparison between cotton and man-made fibre mills invariably favours the latter. Of the women, $16 \%$ in man-made fibre mills developed bronchitis compared with $24 \%$ in cotton mills, and of the men the corresponding figures were $9 \%$ and $23 \%$. The remission rates were $47 \%$ and $33 \%$ for women in man-made fibre and cotton mills respectively and for the men $38 \%$ and $21 \%$. While none of these differences is individually significant they are consistent, and an overall test shows that the environment within the cotton mills was significantly $(\mathrm{P}<0.01)$ more conducive to the development and retention of symptoms of bronchitis 
TABLE 7

Change in Symptoms over Two Years

\begin{tabular}{|c|c|c|c|c|c|c|c|c|c|c|c|}
\hline & & & & & & & & \multicolumn{2}{|c|}{ Incidence of new cases $(\%)^{1}$} & \multicolumn{2}{|c|}{ Remission rate $(\%)^{2}$} \\
\hline & & & & & & & & Women & Men & Women & Men \\
\hline \multicolumn{8}{|c|}{$\begin{array}{l}\text { Bronchitis } \\
\text { Length of exposure (yrs) }\end{array}$} & \multirow{5}{*}{$\begin{array}{l}16 \cdot 1(62) \\
23 \cdot 5(51) \\
19 \cdot 7(66) \\
25 \cdot 5(161)\end{array}$} & \multirow{5}{*}{$\begin{array}{r}8.8(34) \\
16.9(65) \\
22.8(57) \\
32.4(37)\end{array}$} & \multirow{5}{*}{$\begin{array}{l}46 \cdot 7(15) \\
42.9(7) \\
28 \cdot 1(32) \\
33 \cdot 3(81)\end{array}$} & \multirow{5}{*}{$\begin{array}{l}37 \cdot 5(16) \\
30 \cdot 3(33) \\
14 \cdot 0(50) \\
24 \cdot 1(29)\end{array}$} \\
\hline Man-made & fibre & . & .. & . & .. & . & . & & & & \\
\hline $0-9 \quad \ldots$ & $\ldots$ & . & . & . & .. & . & . & & & & \\
\hline $10-19 \ldots$ & .. & . & . & . & . & . & . & & & & \\
\hline $20+\ldots$ & . & . & . & .. & . & . & . & & & & \\
\hline \multicolumn{8}{|c|}{ Smoking (cotton workers) } & \multirow{3}{*}{$\begin{array}{l}20 \cdot 8(149) \\
27 \cdot 1(129)\end{array}$} & \multirow{3}{*}{$\begin{array}{l}19 \cdot 6(51) \\
24 \cdot 1(108)\end{array}$} & \multirow{3}{*}{$\begin{array}{l}39.6(48) \\
27.8(72)\end{array}$} & \multirow{3}{*}{$\begin{array}{l}21 \cdot 7(23) \\
21 \cdot 3(89)\end{array}$} \\
\hline Non- and e & x-smok & & $\ldots$ & $\ldots$ & .. & $\ldots$ & .. & & & & \\
\hline Smokers & $\cdots$ & $\cdots$ & . & . & . & . & . & & & & \\
\hline \multicolumn{8}{|c|}{$\begin{array}{l}\text { Byssinosis } \\
\text { Fine dust }\left(\mathrm{mg} / \mathrm{m}^{3}\right)\end{array}$} & \multirow{7}{*}{$\begin{array}{r}3 \cdot 3(61) \\
9 \cdot 6(83) \\
18 \cdot 3(71) \\
27 \cdot 7(47) \\
21 \cdot 7(60) \\
-\end{array}$} & \multirow{7}{*}{$29 \cdot 4$} & \multirow{7}{*}{$\begin{array}{l}53 \cdot 8(13) \\
62 \cdot 5(8) \\
33 \cdot 3(12) \\
57 \cdot 1(7) \\
34 \cdot 5(29) \\
\quad-\end{array}$} & \multirow{4}{*}{$47 \cdot 1(17)$} \\
\hline $0.25-0.49$ & . & . & . & . & . & . & . & & & & \\
\hline $0.50-0.74$ & $\ldots$ & . & . & . & $\ldots$ & .. & . & & & & \\
\hline $0.75-0.99$ & .. & . & . & . & $\ldots$ & . & . & & & & \\
\hline $1 \cdot 00-1 \cdot 24$ & .. & $\ldots$ & . & . & . & . & . & & & & \multirow{3}{*}{$\begin{array}{l}17 \cdot 4(23) \\
32 \cdot 1(28)\end{array}$} \\
\hline $1 \cdot 25-2 \cdot 38$ & . & $\cdots$ & . & . & $\ldots$ & . & . & & & & \\
\hline No measure & ments & $\cdots$ & . & . & . & . & . & & & & \\
\hline \multicolumn{8}{|c|}{ Length of exposure (yrs) } & \multirow{4}{*}{$\begin{array}{c}7 \cdot 5(53) \\
19 \cdot 5(82) \\
16 \cdot 1(192)\end{array}$} & \multirow{4}{*}{$\begin{array}{l}15 \cdot 2(92) \\
19 \cdot 1(68) \\
18 \cdot 6(43)\end{array}$} & \multirow{4}{*}{$\begin{array}{l}80.0(5) \\
68.7(16) \\
34.0(50)\end{array}$} & \multirow{4}{*}{$\begin{array}{l}33 \cdot 3(6) \\
35 \cdot 9(39) \\
21 \cdot 7(23)\end{array}$} \\
\hline $0-9 \quad \ldots$ & .. & .. & . & . & . & . & . & & & & \\
\hline $10-19$ & . & . & . & . & $\cdots$ & . & $\cdots$ & & & & \\
\hline $20+\ldots$ & . & $\cdots$ & $\cdots$ & $\cdots$ & . & . & . & & & & \\
\hline \multicolumn{8}{|c|}{ Smoking (cotton workers) } & \multirow{3}{*}{$\begin{array}{l}13 \cdot 5(171) \\
17 \cdot 9(156)\end{array}$} & \multirow{3}{*}{$\begin{array}{l}12 \cdot 3(57) \\
19 \cdot 2(146)\end{array}$} & \multirow{3}{*}{$\begin{array}{l}46 \cdot 2(26) \\
44 \cdot 4(45)\end{array}$} & \multirow{3}{*}{$\begin{array}{l}29 \cdot 4(17) \\
31 \cdot 4(51)\end{array}$} \\
\hline Non- and e & $x$-smoke & ers & . & . & . & . & . & & & & \\
\hline Smokers & .. & .. & . & . & . & . & . & & & & \\
\hline
\end{tabular}

1 Number without symptoms on first questionnaire given in parentheses

2 Number with symptoms on first questionnaire given in parentheses

than that within the man-made fibre mills. There is no strong evidence of a relationship between change in bronchitis and length of exposure, and the positive trend of incidence in men is significant only at the $10 \%$ level. The relationship with smoking is consistently in favour of the non/ex-smoker but overall is significant only at the $10 \%$ level.

For byssinosis there is a significant $(P<0.001)$ increase in the incidence of progression from byssinosis grades nil or $\frac{1}{2}$ to grades I or II with increasing dust concentration for women and a significant $(P<0.01)$ negative trend in remission with increasing length of exposure. For men the relationship between the incidence of new cases and dust concentration is negative but not significant; nor is the large difference in remission rates. The incidence is higher in smokers than in non/exsmokers for both sexes, in agreement with the smoking effect on prevalence, but because there were fewer cases it did not reach significance.

\section{Discussion}

Bronchitis

After allowing for age and smoking there was more bronchitis in the cotton mills than in the man-made fibre mills, the difference being greater for the men. For the women the prevalence of bronchitis increased with increasing length of exposure to cotton (Table 1). However, this was not observed for the men, and for neither sex was there any association with dust concentration. There were only two man-made fibre mills in the study, and the excess of bronchitis in the cotton mills depends on how typical these two mills were in regard to the amount of bronchitis expected in non-cotton mills in Lancashire. Some information was given by Lloyd Davies (1971) for men aged 35-64 employed in engineering factories in the North Western region. There was a prevalence of $10.4 \%$ of 'sputum-chest illness syndrome' defined as grades 2 and 3 bronchitis but excluding those who had attacks of increased phlegm only. For men aged 35-64 in our study the prevalence of this syndrome was $9.1 \%$ in the cotton mills and $3.4 \%$ in the man-made fibre mills. Therefore possibly the differences in bronchitis prevalence between cotton and man-made fibre mills were due in part to a low prevalence in the latter. On the other hand, over half the workers in the man-made fibre mills had worked with cotton within five years of entering the 
survey and this would tend to obscure differences between the two types of mills. Also the existence of some association is supported by the data on the change of symptoms over the two-year period (Table 7). Therefore our conclusion is that there is some evidence of a weak association between exposure to cotton dust and the development and retention of bronchitis. Fox, Tombleson, Watt, and Wilkie (1973b) reported a lack of contribution of cotton dust exposure to the prevalence of bronchitis. However, this result was based on a comparison of cotton workers with men working in engineering factories and, as two-thirds of the cotton workers were women, a small difference between cotton and non-cotton workers could have been lost.

\section{Byssinosis}

There was an association with smoking, the smokers having relatively about $40 \%$ more byssinosis of each grade than the non- and ex-smokers after allowing for dust concentration and length of exposure (Table 5). Elwood et al. (1965) and, more recently, Fox, Tombleson, Watt, and Willie (1973a) and Merchant et al. (1973) have also found a higher prevalence of byssinosis in smokers than in nonsmokers.

The prevalence of byssinosis was positively associated with length of exposure for both women and men. There was also a positive association with dust level for women, particularly when dust level was expressed as total dust or in terms of its fine component. For men the association was observed only with the respirable and fine components of dust for men with less than 20 years' exposure. The association between dust level and symptoms of byssinosis also showed up for the women in the relationship between fine dust concentration and the proportion progressing from grades nil or $\frac{1}{2}$ to I or II over a two-year period (Table 7).

Our findings on dose response may be contrasted with those of Roach and Schilling (1960), who related the prevalence of byssinosis of grades I and II with total dust and years of exposure. They reported lower prevalences at the low dust concentrations and higher prevalences at the high dust levels than we have since found. Fox et al. (1973b) gave a dose-response relationship expressing their results in terms of the time-weighted dust measurement, i.e., dust concentration $\times$ length of exposure. This may not be completely valid because, as we discuss later, the dust measurements carried out at the time of the survey may not be applicable to more than a few years previously. However, for comparison we examined our results in a similar way. A curve for each sex was fitted by taking the logit of prevalence as linearly related to the logarithm of time-weighted dust (Fig. 2). For both sexes the fitted curve shows a greater prevalence for a given dust level than that

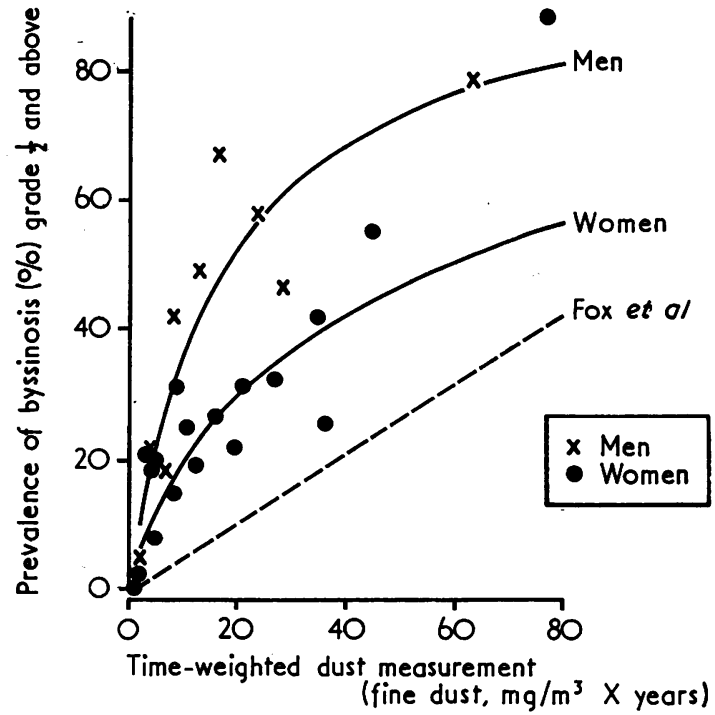

FIG. 2. Prevalence of byssinosis in relation to timeweighted dust measurement. Points represent the means after subdividing by length of exposure and dust concentration (see Tables 3 and 4). For the derivation of the fitted curves see text. The broken line is the relationship given by Fox et al. (1973b).

of Fox et al. (1973b), which refers to the combined sexes. However, for the women the fitted curve does not adequately describe the data and, as we have already shown that smoking and occupation are relevant, we extended the method by including constants for smoking and occupation. The result is shown in Fig. 3 where the dose response curves are given for proportions of smokers of $56 \%$ and $76 \%$ for women and men respectively. The combers, card tenters, and speedframe tenters gave such similar relationships that we have combined them. The ring spinners of our survey gave a relationship similar to that obtained by Fox et al. (1973b) for their sample, of whom $36 \%$ were ring spinners, $29 \%$ were winders and the remainder blow and card room operatives.

The men had higher prevalences than the women but we are unable to determine whether this was a true sex difference or an occupational difference. Over $70 \%$ of the men with dust measurements were strippers and grinders, and this occupation had a high prevalence of byssionsis after allowing for dust concentration, years of exposure, and smoking (Table 6). The men without dust measurements had prevalences of grades $\mathrm{I}$ and II combined of $22.2 \%$ and $18.0 \%$ for non/ex-smokers and smokers respectively, after allowing for length of exposure. These prevalences are similar to the women's (Table 5), suggesting that it is stripping and grinding which carries a higher than average risk of byssinosis 


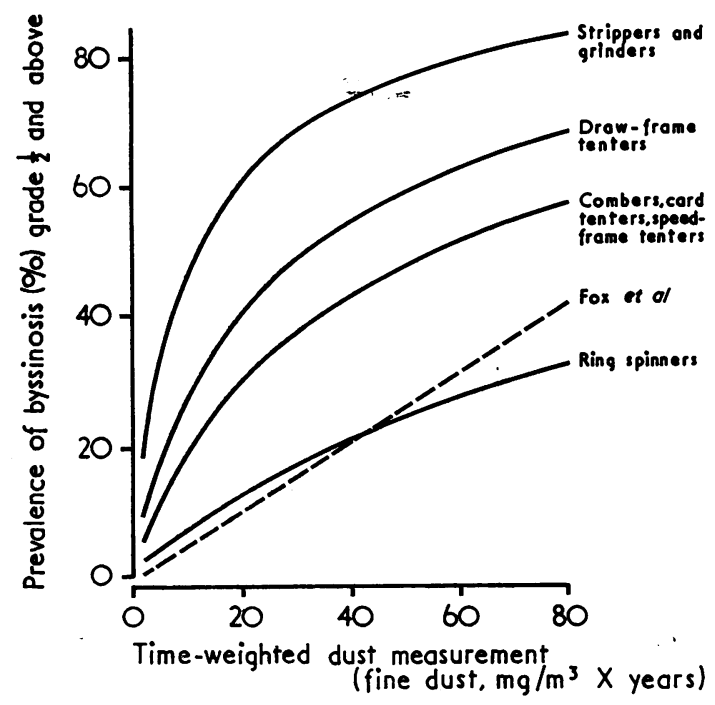

FIG. 3. Prevalence of byssinosis in relation to timeweighted dust measurement and job. For the derivation of the fitted relationships see text. The broken line is the relationship given by Fox et al. (1973b).

rather than a difference in susceptibility between the sexes. There were other differences between the occupations, drawframe tenters having a higher prevalence than would be expected from the dust levels and ring spinners having a lower prevalence. Evidence of differences between occupations may be deduced from Fox et al. (1973b), who found similar dust concentrations in the blow and card rooms to those in the winding rooms but the prevalence of byssinosis in the latter was only about two-thirds that in the former. They also found much less byssinosis in women working in ring rooms, $3 \%$ compared with our $11 \%$, although the mean dust concentrations were very similar.

A possible reason for differences between jobs is a biological difference between the dust at different stages in the processing of cotton. If this were so, the differences could be used as a guide to the identification of active constituents of cotton dust. Another possible contributory factor might be a difference in the relationship between the dust sampling results and the dust levels experienced by individual operatives. This applies particularly to the strippers and grinders and card tenters who move continuously over a working area, giving periodic attention to different machines.

A limitation of our data is that the dust concentrations were measured during the survey only. We have no measurements for earlier periods but we do know that dust suppression devices were introduced into the mills about five years before the survey started.
Therefore conditions before this were almost certainly more dusty. Some comparisons of the effect of the dust suppression equipment, but not for the mills in our survey, were reported by Wood and Roach (1964), who showed that the total dust was reduced to about $30 \%$ of its original value near the carding engines but that there was less change in the fine dust concentration. Therefore in our results, possibly only the relationship for those exposed for less than 10 years is appropriate. For a fine dust concentration of less than $0.75 \mathrm{mg} / \mathrm{m}^{3}$, out of 59 women and 19 men exposed for less than 10 years, one woman had grade $\frac{1}{2}$ byssinosis and one man had grade I. Whether the higher prevalences at these lower dust concentrations are due to the longer exposures or to exposure to higher levels in the past we are unable to determine from our data.

It is not known what component of dust is responsible for causing byssinosis. McKerrow, Roach, Gilson, and Schilling (1962) suggested that the component we term 'respirable' may alone be responsible. Roach and Schilling (1960) considered the component of dust which we term 'fine' appropriate biologically. In their study, $6 \%$ of dust in cardrooms was respirable compared with $20 \%$ in this survey. The difference is probably due to the differential suppression of the coarse dust but does illustrate the importance of knowing the appropriate index to measure so that conclusions are generally applicable. The results of our study show that byssinosis prevalence is positively correlated with total, fine, and respirable dust, but as the fly component of dust cannot penetrate to the upper airways it would be expected that only dust below $2 \mathrm{~mm}$ length could be important. We conclude therefore that in assessing the environment of cotton mills it is at least necessary to measure the concentration of fine dust ( $<2 \mathrm{~mm}$ length).

It is also clear that, as long as the active agent remains unknown, the dose response based on mass concentration of dust found in one situation may not necessarily be applicable to all other situations. Nevertheless there is a need for standards which will prevent overexposure to cotton dust at the present time and in the immediate future. This need is met by two standards; one is the threshold limit value of $1 \mathrm{mg} / \mathrm{m}^{3}$ for total dust (Roach and Schilling, 1960; American Conference of Governmental Industrial Hygienists, 1971), the other is the hygiene standard of $0.5 \mathrm{mg} / \mathrm{m}^{3}$ of fine dust, i.e., total less fly of more than $2 \mathrm{~mm}$ length, recommended by the British Occupational Hygiene Society (1972). In view of the uncertainty of a single figure being applicable in all circumstances, there is a need for routine monitoring of the dust levels in cotton mills supported by biological monitoring of exposed personnel to ensure that present standards are providing a reasonable degree of protection. 
We are greatly indebted to the management, workers, and welfare staffs of all the mills without whose cooperation the survey could not have been made. The British Spinners' and Doublers' Association, the United Textile Factory Workers' Association and the National Union of Textile and Allied Workers also gave us valuable support.

The late Dr. C. B. McKerrow was actively associated with this survey throughout and we owe a great deal to his inspiration.

Dr. J. C. Gilson and Professor R. S. F. Schilling were involved in the planning of the survey and we are grateful for their advice and encouragement throughout. We are indebted to Mr. A. W. Hyett who designed and made the modifications to the dust sampling equipment.

We also wish to thank Professors R. E. Lane and T. S. Scott of the Department of Occupational Health of Manchester University for their help; Dr. T. A. Lloyd Davies, now Chief Medical Adviser, Department of Employment for his support; the Medical Research Council for a grant to M.K.B.M.; and finally the technicians and other helpers who were involved in the day to day operation of the survey.

\section{References}

American Conference of Governmental Industrial Hygienists (1971). Documentation of the Threshold Limit Values for Substances in Work Room Air. A.C.G.I.H., P.O. Box 1937, Cincinnati, Ohio, 45201.

Berry, G. (1970). Parametric analysis of disease incidences in multiway tables. Biometrics, 26, 572-579.

- McKerrow, C. B., Molyneux, M. K. B., Rossiter, C. E. and Tombleson, J. B. L. (1973). A study of the acute and chronic changes in ventilatory capacity of workers in Lancashire cotton mills. British Journal of Industrial Medicine, 30, 25-36.

British Occupational Hygiene Society (1972). Hygiene standards for cotton dust. Annals of Occupational Hygiene, 15, 165-192.

Elwood, P. C., Pemberton, J., Merrett, J. D., Carey, G. C. R., and McAulay, I. R. (1965). Byssinosis and other respira- tory symptoms in flax workers in Northern Ireland. British Journal of Industrial Medicine, 22, 27-37.

Fox, A. J., Tombleson, J. B. L., Watt, A., and Wilkie, A. G. (1973a). A survey of respiratory disease in cotton operatives. Part I. Symptoms and ventilation test results. British Journal of Industrial Medicine, 30, 42-47.

,$--1-$ and - (1973b). A survey of respiratory disease in cotton operatives. Part II. Symptoms, dust estimations, and the effect of smoking habit. British Journal of Industrial Medicine, 30, 48-53.

Lloyd Davies, T. A. (1971). Respiratory Disease in Foundrymen: Report of a Survey. HMSO, London.

McKerrow, C. B., Roach, S. A., Gilson, J. C., and Schilling, R.S. F. (1962). The size of cotton dust particles causing byssinosis: an environmental and physiological study. British Journal of Industrial Medicine, 19, 1-8.

Medical Research Council (1960). Standardised questionnaires on respiratory symptoms. British Medical Journal, 2, 1665.

- (1966). Chronic bronchitis and occupation. British Medical Journal, 1, 101-102.

Merchant, J. A., Lumsden, J. C., Kilburn, K. H., O'Fallon, W. M., Ujda, J. R., Germino, V. H., and Hamilton, J. D. (1973). An industrial study of the biological effects of cotton dust and cigarette smoke exposure. Journal of Occupational Medicine, 15, 212-221.

Molyneux, M. K. B. and Tombleson, J. B. L. (1970). An epidemiological study of respiratory symptoms in Lancashire mills, 1963-66. British Journal of Industrial Medicine, 27, 225-234.

Roach, S. A. and Schilling, R. S. F. (1960). A clinical and environmental study of byssinosis in the Lancashire cotton industry. British Journal of Industrial Medicine, 17, 1-9.

Schilling, R. S. F. (1956). Byssinosis in cotton and other textile workers. Lancet, 2, 261-265.

Wood, C. H. and Roach, S. A. (1964). Dust in card rooms: a continuing problem in the cotton-spinning industry. British Journal of Industrial Medicine, 21, 180-186.

Received for publication May 3, 1973.

Accepted for publication August 3, 1973. 